\title{
JOVENS, IMAGENS DE SI E A CIDADE: DISCURSOS EM MOVIMENTO
}

\section{THE YOUTH, THE IMAGES OF THEIR SELVES AND THE CITY: SPEECHES IN MOVEMENT}

\author{
Déborah Levitan ${ }^{1}$ \\ Janaína Rocha Furtado ${ }^{2}$ \\ Andréa Vieira Zanella ${ }^{3}$
}

Levitan D, Furtado JR, Zanella, AV. Jovens, imagens de si e a cidade: discursos em movimento. Rev Bras Crescimento Desenvolvimento Hum. 2009; 19(2): 283-296.

\section{Resumo:}

A polifonia da cidade, na emergência dos ritmos e sentidos urbanos, as juventudes apresentam-se como vozes ativas que fazem falar ao urbano sobre suas necessidades e desejos. Compreender as relações existentes entre juventude e cidade, bem como os sentidos que permeiam este momento da vida para algumas jovens foi o objetivo deste trabalho. Realizou-se entrevistas com cinco jovens, de onze a quatorze anos, residentes em um bairro popular de Florianópolis/SC e seus discursos foram analisados a partir das contribuições de Bakhtin (1990) e Vygotski (2000). A leitura do material transcrito permitiu organizar as informações em unidades temáticas de análise, intituladas: Criança, jovem, adolescente? Não sei! Imagens de si; Vozes entrelaçadas: silêncios e gritos na juventude, e Jovens meninas: histórias e percursos num bairro popular de Florianópolis. Os resultados permitem compreender a trama intrincada das relações e vozes sociais que participam no processo de constituição da imagem de si das jovens investigadas e o modo como vão se apropriando das falas de muitos outros, o que se objetiva em seus discursos. Constatou-se, nesse sentido, que os discursos, de modo geral, revelam as múltiplas vozes, audíveis e inaudíveis, que constituem as condições singulares/coletivas das jovens entrevistadas e que são (re)produzidas nos espaços onde vivem, sendo a Associação de Moradores um dos lugares mais significativos para sua constituição como sujeitos.

Palavras-chave: juventude; cidade; imagem de si; jovens; discurso.

Acadêmica do Curso de Psicologia da Universidade Federal de Santa Catarina (UFSC), Bolsista IC-CNPq

Mestre em Psicologia pela Universidade Federal de Santa Catarina (UFSC)

Professora do Departamento de Psicologia e do Programa de Pós-Graduação em Psicologia da Universidade Federal de Santa Catarina, bolsista produtividade do CNPq

Pesquisa realizada com o apoio financeiro da FAPESC.

Correspondência para Déborah Levitan. Rua das Palmeiras Nativas, nº. 200 - Lagoa da Conceição. Florianópolis/SC. CEP: 88062-010. Telefone e Fax: (48) 32320516 Email: delevitan@gmail.com

Financiamento FAPESC - No do processo: 12223/2007-8 


\begin{abstract}
:
It is in the polyphony of the city, in the emergence of the urban rhythms and senses that youths present themselves as active voices that are capable to dialogue with the urban about their own needs and desires. To comprehend the relationships between youth and the city, as well as the meanings that involve this moment of life for some young girls were the main goals of this research. The researchers interviewed five young girls, with ages between eleven to fourteen, that were residents of a popular neighborhood in Florianópolis/SC. The speeches of those young girls were analyzed by the contributions of Bakhtin (1990) and Vygotski (2000). The reading of the material allowed the organization of the information in thematic units of analysis, entitled: Child, young, adolescent? I don't know! Images of itself; Interlaced voices: silence and shouts in the youth, and Young girls: histories and trajectories in a popular neighborhood of Florianópolis. The results permitted to understand the intricate scheme of social voices and relationships, that participate in the process of itself's image's constitution of the investigated young girls, and the way they appropriate the speeches of many "others" in their own speech. This study demonstrates that the speeches, generally, reveal the multiple voices, audible or not, that constitute the collective and singular conditions of the investigated young girls and that these voices are (re)produced in the spaces where they live; the Neighborhood Association is one of the most significant places for those young girls' constitution as suibject.
\end{abstract}

Key words: youth; city; image of itself; young people; speeches.

\section{INTRODUÇÃO}

Adolescência e juventude têm sido temas de discussões recorrentes em pesquisas científicas e ações políticas na esfera pública, privada e do terceiro setor. Debates acerca desta temática têm chamado a atenção para a demarcação da pluralidade e diversidade deste momento da vida, das contradições que o caracterizam e dos problemas que a maioria dos jovens enfrenta. ${ }^{1-5}$

Consoante com esses debates, discussões foram travadas acerca da definição do que vem a ser adolescência e juventude e as faixas etárias que as delimitam. Segundo a Organização Mundial de Saúde (OMS), a adolescência constitui um processo biológico maturacional, no qual se aceleram o desenvolvimento cognitivo e a estruturação da personalidade. Por juventude compreendem-na como uma categoria sociológica que implica em uma prepara- ção dos indivíduos para a vida adulta e compreende a faixa etária de 15 a 24 anos.

Para o Conselho Nacional da Juventude, todavia, a juventude compreenderia a faixa etária entre 15 e 29 anos. O ProJovem reformulado introduz no Brasil um padrão internacional de conceituação de juventude, definindo-a na faixa etária entre 15 e 29 anos, na qual é possível identificar três grupos: os adolescentes-jovens (15 a 17 anos), os jovens-jovens (18 a 24 anos) e os jovens-adultos ( 25 a 29 anos).

Coimbra, Bocco e Nascimento 6 , por sua vez, chamam a atenção para o entendimento psicologizante acerca da adolescência, que vigorou durante muito tempo no meio acadêmico e social mais amplo, e que ainda se encontra no seio do pensamento biomédico. Acreditam que o conceito adolescência acabou tornando-se por demais estigmatizado, referindo-se a estreitas faixas etárias e a seus respec- 
tivos padrões de comportamento, adequados ou inadequados. O conceito de juventude ou jovem, por sua vez, "poderia permitir a abertura de espaços para a diferença que existe nos processos e nos acasos dos encontros".

Partindo da compreensão de que o sujeito se constitui por meio das relações com outras pessoas estabelecidas no decorrer de sua vida, em contextos sócio-históricos particulares, problematizam-se as concepções que consideram a adolescência como um período estanque, universal e rígido. Como uma categoria sociológica, sabe-se que ocorre um processo sociocultural demarcado pela preparação dos indivíduos para assumirem o papel de adulto na sociedade, no plano familiar e profissional.

Não há, no entanto, como definir com exatidão quais seriam as características e comportamentos específicos deste momento de vida e, tampouco, quais as idades precisas que o delimitam. Como bem coloca Dayrell", "Dessa discussão, entendemos a juventude como parte de um processo mais amplo de constituição de sujeitos, mas que tem especificidades que marcam a vida de cada um. A juventude constitui um momento determinado, mas não se reduz a uma passagem; ela assume uma importância em si mesma".

Neste sentido, optamos pelo termo juventude, em concordância com as críticas tecidas por Coimbra, Bocco e Nascimento ${ }^{6}$ e Dayrell $^{7}$, mas não no singular: falaremos em "juventudes, no plural, e não de juventude, no singular, para não esquecer as diferenças e desigualdades que atravessam esta condição" ${ }^{8}$. O uso do plural indica o reconhecimento de que a juventude é uma condição existente em variados grupos sociais, mas que pode ser significada distintamente por cada um deles, enfatizando os diferentes modos de vivência de tal momento.

Em contextos de ausência e/ou negligência de direitos, por sua vez, os jovens apresentam algumas peculiaridades na medida em que se encontram imersos em uma realidade marca- da pela violência, tráfico de drogas, evasão escolar, trabalho infantil, bem como restrição ao acesso às oportunidades de saúde, educação, trabalho, esporte, lazer e cultura. Essas condições adversas têm representado um desafio às políticas públicas e às propostas de intervenção que objetivam sua transformação..$^{9,10}$

De acordo com as pesquisas realizadas por Castro, Abramovay, Rua e Andrade ${ }^{4}$ em relação às diversas experiências brasileiras com jovens em situações de pobreza, um aspecto comum sobre o cotidiano de jovens que vivem em bairros de setores populares é o caráter rotineiro de suas vidas, incluindo as atividades de lazer. Sabe-se da enorme carência de atividades e espaços de lazer nessas áreas, bem como da falta de meios econômicos que lhes possibilitem o usofruto de bens culturais urbanos.

A dificuldade no acesso aos bens culturais disponíveis e a falta de produções culturais e espaços com foco na população jovem de periferia, seus hábitos, valores e linguagens, promoveria, segundo Castells ${ }^{11}$, que estes mesmos jovens produzessem uma "desordem alternativa feita de sua negação a um sistema que os nega”.

A falta desses equipamentos culturais evidencia a realidade dura e com pouca sensibilidade por parte do poder público em relação às condições de vida dessas pessoas. No entanto, embora sejam obliteradas as possibilidades de que, com as condições que têm, essa realidade seja transformada e resignificada, os jovens resistem e podem negar o sistema que os nega.

Pesquisa realizada por Coimbra ${ }^{12}$ explicita o poder da mídia na construção do mito das classes sociais de baixo poder aquisitivo como "classes perigosas", e os índices de assassinatos de jovens em periferias urbanas apresenta-se como indicador de que a imagem da juventude empobrecida do país vem sendo construída sob a égide do medo, da falta de perspectivas, da marginalidade em curso.

Por sua vez, diferenças sociais são continuamente construídas e solidificadas em contex- 
tos urbanos singulares, os quais instituem formas de ser e modos de vida. Ao compreender as cidades e suas possibilidades de significar e viver o cotidiano como discursos e narrativas, deparamonos com a multiplicidade de vozes e sentidos enunciando aos seus ilimitados cantos as diversas condições sociais ali existentes.

A distribuição das pessoas e demais seres vivos nos espaços urbanos e os processos de marginalização político-sociais acontecem mutuamente e são interdependentes. Uma cidade não é a mesma para todos os seus habitantes, mas significada diversamente pela qualidade das relações que potencializam ou não um sujeito em devir, abarcando as dimensões ética, política e estética. Não podemos, portanto, pensar as juventudes e as imagens que jovens formam acerca de si mesmos sem considerar os contextos urbanos nos quais estão inseridos e que compõem um horizonte de possibilidades e condições de viver e significar-se como sujeitos.

A metrópole, centro de cultura e diversão dos jovens de classes abastadas é e não é a mesma metrópole dos jovens de periferia, desapropriados de direitos e reprimidos em suas próprias formas e maneiras de divertir-se e produzir cultura nestes espaços. Certamente, os jovens mais favorecidos economicamente também sentem-se oprimidos pela violência e medos que acreditam estar localizados naquela outra juventude urbana. Mito comumente criado e recriado pela mídia de que o perigo mora no morro e nas favelas e não nas diferenças socias produzidas pelos meios de comunicação, ratificadas pelas políticas públicas e hierarquicamente valorizadas pelo coletivo urbano.

Nas cidades, coompreendendo-as também como espaços geográficos, delimitam-se não somente barreiras físicas mas também, e neste sentido orientamos esta reflexão, ideológicas entre as classes sociais distintas. Dos territórios e suas determinações econômicas e sociais, transcende-se para uma ordem do discurso urbano, do qual emergem as diferentes apropriações simbólicas que os jovens e as juventudes produzem acerca deste momento da vida, experienciada nestes contextos multiformes e multifacetados.

Na polifonia da cidade, na emergência dos ritmos e sentidos urbanos, as juventudes apresentam-se como vozes ativas que fazem falar ao urbano sobre suas próprias necessidades e desejos. No urbano e a partir dele imagens pólis-formes das juventudes sobre si podem mostrar-nos um caleidoscópio irreverente, expressão da típica multipli-cidade.

Diretamente relacionada ao (re)(des)conhecimento dessa imagem, buscouse compreender como os jovens constroem imagens de si, fundamental para a compreensão de suas ações presentes e futuras, de seus projetos, de algum vir a ser. Marginalizados e/ ou reconhecidos como marginais em potencial, como se (re)conhecem esses jovens? Quais as imagens que têm de si? Almejando responder a essas perguntas, entrevistamos jovens participantes de uma oficina de teatro-improvisação oferecida em uma Associação de Moradores de um bairro popular da cidade de Florianópolis/SC.

O objetivo da pesquisa é, portanto, compreender os discursos dessas jovens sobre as imagens que constroem de si. Para cumprir esse objetivo, foram analisadas e problematizadas as diferentes vozes sociais que aparecem nestes discursos e que se apresentam como constitutivas das jovens entrevistadas, bem como pôde-se identificar as concepções de juventude que essas jovens apresentam e a relevância do contexto urbano no qual estão inseridas.

\section{MÉTODO}

Foram sujeitos desta pesquisa cinco jovens com idades entre 11 a 14 anos, do sexo feminino, que participaram de oficinas estético-criadoras de teatro ministradas na Associa- 
ção do bairro em que residiam. Segundo o Ministério da Saúde ${ }^{13}$, a adolescência estaria circunscrita na segunda década da vida (de 10 a 19 anos), sendo, portanto as jovens entrevistadas reconhecidas pelas autoridades em saúde brasileiras como adolescentes.

O curso de teatro/improvisação foi realizado através de encontros semanais com duração de aproximadamente três horas cada, por um período de três meses. Realizou-se no total 10 encontros, entre setembro e novembro de 2007. Frequentaram a oficina em média cinco a dez jovens, majoritariamente do sexo feminino, sendo que somente no primeiro encontro contou-se com a presença de um jovem do sexo masculino. Faz-se importante ressaltar que o número de participantes não foi constante ao longo do curso e que nem todas as participantes frequentaram todos os encontros.

As jovens participantes da pesquisa e seus representantes legais, uma vez que os jovens tinham idade inferior a 18 anos, foram esclarecidos quanto aos objetivos da pesquisa e seus procedimentos e assinaram um Termo de Consentimento Livre e Esclarecido, no qual autorizaram o uso e divulgação de suas imagens e falas pelas pesquisadoras, sendo resguardadas de qualquer identificação.

Esclarece-se que esta pesquisa foi aprovada pelo Comitê de Ética na Pesquisa ( $N^{\circ} 190 /$ 2007) com Seres Humanos da Universidade Federal de Santa Catarina, sendo observados para seu desenvolvimento os princípios que regulamentam a realização de pesquisas com seres humanos estabelecidos tanto pelo Ministério da Saúde quanto pelo Conselho Federal de Psicologia.

A coleta de informações junto às jovens compreendeu entrevistas realizadas individualmente, com roteiro prévio, na própria Associação de Moradores em dois momentos: no decorrer das semanas iniciais da referida oficina, com sete participantes, e após três meses do término das oficinas de teatro/improvisa- ção, em março de 2008, depois das férias escolares, com cinco das sete participantes anteriormente entrevistadas.

Todas as entrevistas foram gravadas com o auxílio de um aparelho gravador digital e filmadora e transcritas integralmente. Foram considerados para o tratamento de dados e posterior análise apenas as informações obtidas nas entrevistas das participantes que realizaram as duas entrevistas: iniciais e finais.

Foi escolhida como procedimento para a coleta de informações a entrevista aberta com questões norteadoras, a qual se caracteriza por permitir participação ativa tanto do investigado quanto do investigador na produção do conhecimento. ${ }^{14}$

Para a análise das entrevistas iniciais e finais utilizou-se a análise do discurso, partindo das teorias de Bakhtin ${ }^{15}$ e Vigotski ${ }^{16}$, de acordo com os pressupostos epistemológicos do enfoque Histórico-Cultural em Psicologia. Tal perspectiva metodológica possibilita investigar a materialidade discursiva a partir de suas condições de produção. Assim sendo, buscou-se, para além dos sentidos expressos nos discursos, articular as várias dimensões que atuam na produção destes sentidos: a situação concreta, o contexto histórico social e ideológico, os interlocutores e as múltiplas vozes sociais que se apresentam nos discursos.

\section{RESULTADOS}

Ao conceber juventude como uma condição que existe em vários grupos sociais, significada distintamente por cada um deles, e não somente como uma faixa etária com uma mesma configuração, faz-se importante compreender a que juventude esta pesquisa está se referindo: quem são esses jovens que dialogam com as pesquisadoras?

Na tabela consta o nome, sexo e idade dos sujeitos de pesquisa nas entrevistas iniciais 
Tabela 1 - Nomes, idades e sexo dos sujeitos de pesquisa

\begin{tabular}{lccc}
\hline Nome & Idade (Entrevista Inicial) & Idade (Entrevista Final) & Sexo \\
\hline Valéria & 13 & 14 & Feminino \\
Poliana & 13 & 13 & Feminino \\
Mônica & 13 & 13 & Feminino \\
Fabiana & 12 & 12 & Feminino \\
Kátia & 11 & 11 & Feminino \\
\hline
\end{tabular}

e finais. A fim de resguardar a identidade das participantes, utilizou-se nomes fictícios.

É mister esclarecer que as entrevistas finais não foram realizadas com todas as participantes das entrevistas iniciais porque duas delas encontravam-se inacessíveis - uma havia se mudado para outra cidade e a outra não participava de mais nenhuma atividade da Associação de Moradores, não deixando telefone para contato.

As jovens que participaram da pesquisa moram com a família, que em sua maioria é constituída por um número significativo de irmãos (em média de 4 a 6 irmãos) e tem a mãe como centro do núcleo familiar. Das cinco entrevistadas, quatro delas não moram com o pai, estando este último afastado da vida das participantes.

Todas as jovens entrevistadas eram estudantes da mesma escola localizada em um bairro popular de Florianópolis e moradoras deste mesmo bairro. Quatro das cinco participantes não nasceram em Florianópolis (duas vieram de Foz do Iguaçu, uma de Videira e outra de São Paulo) e moravam há mais de três anos nesta cidade. Todas frequentavam a escola no período da manhã e a tarde participavam de atividades oferecidas pela Associação de Moradores.

Além desta caracterização é possível, através da análise dos discursos produzidos nas entrevistas, conhecer o que essas jovens falam de si e, através dessa análise, compreender como as vozes de um outro aparecem em seus discursos.
O discurso caracteriza-se como um conjunto de enunciados que veiculam sentidos, não por si mesmos enquanto sentidos "puros" e originais ali desvelados e que representam identicamente o mundo, mas fundamentalmente sentidos que se constituem em unidades de interação social, em práticas sociais concretas que implicam uma estrutura social e forças materiais que possibilitam a emergência de certos gêneros discursivos, ou seja, certos estilos, formas, composições e usos de linguagem. ${ }^{17}$

Segundo Bakhtin ${ }^{15}$ e Vigotski ${ }^{16}$, não é possível compreender o ser humano, sua vida, suas atividades, suas lutas, suas criações, senão por meio dos signos, da linguagem e dos processos de significação. Assim, as entrevistas e as filmagens permitiram compor o contexto das atividades, resgatar e produzir seus sentidos junto às jovens, localizando os contextos de enunciação, as histórias dessas jovens e as transformações dos processos investigados.

Almejou-se, portanto, compreender o objeto abarcando as contradições, os movimentos e as condições reais, sociais e históricas que constituem o objeto desta pesquisa - a saber, os discursos de jovens e as imagens que constroem de si. A análise dos processos envolvidos partiu de uma investigação que considerou a interdependência dos fenômenos e suas mediações efetivas para reconstruir o curso de seu desenvolvimento e suas transformações, alicerçadas nas condições sócio-históricas do momento em que se vive. 
A partir da leitura e releitura das entrevistas foi possível organizar as informações em unidades temáticas de análise, que emergiram do próprio discurso das jovens e que foram elaboradas a partir das perguntas que nortearam as entrevistas iniciais e finais, sendo as mesmas intituladas: 1)Criança, jovem, adolescente? Não sei! Imagens de si; 2)Vozes entrelaçadas: silêncios e gritos na juventude e 3)Jovens meninas: histórias e percursos num bairro popular de Florianópolis.

\section{Criança, jovem, adolescente? Não sei! Imagens de si}

Quando às jovens foi indagado se consideravam-se criança, adolescente ou jovem, duas delas responderam que são pré-adolescentes, duas que são crianças e uma simplesmente disse "Não sei!"

De fato, é importante reconhecer que essa é uma pergunta constrangedora a se fazer a alguém e cuja importância está para inúmeras outras pessoas, inclusive para nós, porém, parece pouco significativa para as jovens entrevistadas. Para elas, qual a diferença real entre ser criança, adolescente ou jovem? Há alguma mudança significativa em suas vidas ao se reconhecerem em uma dessas classificações? As mudanças estariam nos termos ou nelas, nas suas vivências, no dia-a-dia?

As respostas nos fazem refletir sobre o que produzem esses diferentes conceitos. O que as jovens dizem, os enunciados "préadolescente" e "criança”, ao mesmo tempo em que refletem uma dada realidade, ou seja, um horizonte social mais amplo no qual se configura que meninas da idade delas são pré-adolescentes ou adolescentes; também refratam essa mesma realidade ${ }^{4}$, e nos dizem como essas jovens, cada qual com sua história, situam-se e sentem-se diante destas categoriza- ções. Ao mesmo tempo em que estes signos registram as transições das idades, as mudanças sociais engendradas nos sujeitos, registram também, enquanto signos ideológicos, as mudanças sociais acerca do que seja a adolescência.

A condição de ser ou não adolescente ou ser criança, expressa nas vozes destas jovens, é produzida nas relações sociais por elas vivenciadas e que possibilitam um dizer de si, a construção de uma imagem de si. Imbrica-se nesse sentido o coletivo e o singular, pois "a consciência adquire forma e existência nos signos criados por um grupo organizado no curso de suas relações sociais”. ${ }^{15}$

Voltemos às jovens e seus discursos: enquanto algumas das entrevistadas se situam no entre meio, no entre lugar, onde não sabem dizer se são uma coisa ou outra, criança ou jovem, dizendo objetivamente e, não obstante, a partir de vozes silenciosas que ecoam nas suas vozes, "eu sou pré-adolescente”; outras duas se colocam ainda como crianças. Pertinente pensar: onde está a diferença? Seriam as faixas etárias os aspectos delimitadores deste período?

Segundo os critérios da OMS, todas as jovens entrevistadas estariam entre a pré-adolescência e adolescência. E, certamente, duas destas jovens parecem estar bem a par destas conformações. No entanto, duas jovens ainda se consideram crianças. Seus discursos refletem, justamente, o que Dayrell ${ }^{7}$ destaca, ou seja, que a adolescência não se reduz a uma simples passagem, mas ganha importância por si mesma. E as contradições engendradas por essas categorias, bem como da própria realidade em transformação, fica explícita na voz daquela jovem que responde, ao ser questionada se considerava-se criança adolescente ou

4 Essa reflexão apóia-se na compreensão de signo ideológico de Bakhtin. ${ }^{15}$ Para o autor, "Um signo não existe apenas como parte de uma realidade; ele também reflete e refrata uma outra. Ele pode distorcer essa realidade, ser-lhe fiel, ou apreendê-la de um ponto de vista específico, etc.”. 
jovem, um imenso “Não sei!”. De fato, pra que saber?

Esse não saber se se é criança, adolescente ou jovem apresenta-se como expressão de um processo de transição, caracterizado pela indefinição da condição presente. Por sua vez, é importante considerar que cada pessoa vivencia os momentos de vida de modo particular, sem necessariamente separá-los por períodos. Quem separa é quem pergunta. E esse "Não sei”, mais questionador do que imperativo, reflete-nos enquanto pesquisadores. Este Outro que vem perguntar quem você é. O que você se considera dentre este punhado de signos e valores.

Como destaca Bakhtin ${ }^{15}$, a palavra dirige-se a um interlocutor e toda e qualquer enunciação é determinada não só pela situação mais imediata, mas também pelo meio social mais amplo. Este "Não sei” tão preciso, portanto, é fruto tanto da pergunta imediata, direcionada pela entrevistadora, mas, fundamentalmente, revela as contradições sociais acerca da adolescência e juventude.

Se as perspectivas biologicistas e maturacionais não dão conta das diferenças e singularidades implicadas nestes momentos da vida em que parece que não somos nem isso nem aquilo, não quer dizer que o corpo não se modifique. Aliás, essas mudanças evidenciamse como o substrato material para as construções simbólicas em relação à adolescência.

Essa relação entre a condição corporal e o discurso sobre si produzido com a mediação do discurso de um outro sobre si, explicitase em outro momento. Após perguntar "quais as características de um adolescente/jovem para você?”, Valéria fala várias coisas a respeito do que a mãe dela acredita ser uma adolescente e diz: "Eu acho que é depois da menstruação".

A menstruação da menina é socialmente reconhecida como um sinal que demonstra que está pronta para efetuar a passagem para a adolescência. Socialmente, diz-se que após menstruar a jovem deixa de ser criança e passa a ser uma mocinha. Valéria repete esse discurso e enuncia a menstruação como um rito de passagem. A menstruação envolve outros questionamentos nos dias atuais. Sabe-se, por exemplo, que as meninas tem menstruado cada vez mais cedo nos últimos anos. Podemos pensar que não são apenas processos biológicos os norteadores para compreender a adolescência ou juventude, mas, de modo mais complexo, as transformações culturais, econômicas, políticas e sociais.

Entretanto, ainda é necessário seguirmos numa outra reflexão. Se cada juventude é demarcada por condições afetivo-sociais particulares, os discursos dessas jovens também refletem um sentido compartilhado acerca da juventude e de algumas características que lhe seriam correspondentes. Por vezes, alguns jovens experimentam um estranhamento no que se refere às dinâmicas do namoro, dos interesses afetivo-sexuais que estão entrando em cena no conjunto das relações que vivenciam.

Ao perguntarmos a Kátia se há aspectos ruins ou desagradáveis em estar vivenciando a adolescência, ela responde: "É quando eles incomodam a gente (...) Os guris". Essa mesma jovem referia-se a si mesma ainda como uma criança. Para ela, os meninos ainda incomodam, perturbam as brincadeiras e atividades de seu grupo.

Se por um lado elas se sentem atraídas pelos apelos do universo jovem, da questão da descoberta da sexualidade, do corpo, por outro lado, o brincar ainda é uma forma de se expressar e viver o cotidiano. Os "não sei", enunciados com frequência ao se referirem a si mesmas, às suas condições, tornam-se significativos à medida que definem e fazem referência justamente às transições, indefinições e mudanças que se apresentam na vida das jovens.

As falas aparentemente contraditórias de quem se considera criança, mas preocupase com o corpo e futuro profissional; ou ao contrário, de quem se considera pré-adolescen- 
te, mas ainda gosta de brincar - refletem e refratam relações antitéticas e evidenciam as nuances e sentimentos de não-pertencimento a uma única e rígida classificação.

Múltiplas vozes vão compor estes enunciados, uma vez que do coletivo ao singular e no movimento inverso, as jovens falam de umas certas juventudes. Quando lhes eram feitas perguntas sobre si, as jovens tinham dificuldade de respondê-las em um primeiro momento. No entanto, quando se era perguntado a respeito de jovens em geral, elas respondiam com mais facilidade e os seus discursos se baseavam nas falas sobre si mesmas, evidenciando o movimento, que do singular ao coletivo, expressa o singular.

Mas que vozes são essas que se apresentam? De que maneira elas compõem o tom das juventudes e seus enunciados?

\section{Vozes entrelaçadas: silêncios e gritos na juventude}

A dificuldade de definir-se enquanto criança, adolescente ou jovem relaciona-se também às diversas contradições e indefinições apresentadas nos discursos das diferentes instâncias - sociedade, família, ciências - a respeito desse momento da vida. Tornam-se, estes discursos, vozes que ecoam e constituem os discursos destas jovens sobre si mesmas. Não se tratam de discursos puros, portanto, mas, fundamentalmente, de discursos produzidos em determinados contextos e a partir de discursos outros, caracterizando-se como dialógicos e polifônicos. A partir destes, as jovens engendram movimentos de apropriação da realidade e objetivação da mesma na construção e percepção da imagem de si.

Nessa perspectiva, no decorrer das análises foi possível observar como o discurso das jovens é constituído por diferentes vozes apropriadas por elas a partir das relações sociais em que estão inseridas ou que fizeram parte de sua história. Os discursos revelam as vozes principalmente da família, amigos e dos mui- tos 'outros' que caracterizam a cultura, como essas vozes se entretecem e ecoam e como esses 'outros' constituem o 'eu'.

Valéria, ao ser indagada a respeito do que considera como características de um jovem/adolescente, responde: "É que a minha mãe sempre fala que a adolescência é a fase mais difícil, né? Que começa a namorar, ... ficar deitada, assim, não fazer nada. Mas eu não acho isso, eu acho que adolescente não pensa só em namorar, em ficar sentada, deitada. Não sei."

A voz da mãe de Valéria, que considera adolescente quem não faz nada, ecoa no discurso de Poliana ao ser indagada como são os jovens da comunidade a que ela pertence:

"Entrevistadora: E como é que são as outras pessoas que moram aqui na comunidade, da tua idade?

Poliana: São chatas.

Entrevistadora: Por quê?

Poliana: Eu acho chata. Mas têm algumas que são legais. Que eu considero legais. Porque a maioria delas não gostam de brincar.

Entrevistadora: Não gostam de brincar? E você gosta?

Poliana: Ah, eu gosto.

Entrevistadora: E o que as pessoas que não gostam de brincar fazem?

Poliana: Ficam conversando.

Entrevistadora: Conversando?

Poliana: Sentadas olhando uma para a cara do outro. Ficam paradas.

Entrevistadora: E tem algum lugar que elas ficam sentadas?

Poliana: Ah, lá na esquina mesmo. Ficam conversando.”

O “ficar só conversando", para Poliana, significa não fazer nada, já que não se identifica com essa atividade. Percebe-se as triangulações das vozes que constituem as jovens enquanto sujeitos: a voz da mãe de Valéria ("ficar deitada, assim, não fazer nada”) está presente no seu discurso, ao mesmo tempo em que aparece no discurso da Poliana, quando afirma que 
pessoas da sua idade "ficam sentadas olhando uma para cara do outro. Ficam paradas”. $\mathrm{Ou}$ seja, há um movimento dos discursos que revela a constituição do sujeito como singular e coletivo, pois as jovens recolhem os discursos da família e da situação social em que estão inseridas e compõem os seus próprios/alheios discursos.

A própria Valéria, em momento posterior, tornará audível a voz de sua mãe no relato de suas falas a respeito dela mesma, de suas ações:

"Entrevistadora: Como sua família te vê? O que gostam em você? O que não gostam em você?

Valéria: Não gostam é que sempre, tem vezes assim que, que eu fico só sentada, assim, daí minha mãe manda eu lavar a louça, varrer a casa daí eu não gosto. Daí eu fico sentada. Ou às vezes eu subo pro quarto e finjo que to dormindo. Daí a minha mãe fica me chamando lá e eu, eu finjo que to dormindo. Daí ela vai lá em cima, daí eu cubro a cabeça, e ela pensa que eu to dormindo e desce. Eu acho que é isso que ela não gosta.

Entrevistadora: E o que ela gosta?

Valéria: Não sei o que ela gosta... Quando eu cuido dos meus irmãos”.

As palavras que eram atribuídas ao discurso de um outro - o "ficar deitada", que caracteriza o adolescente para a mãe - tornamse próprias, em um movimento em que me aproprio do discurso do outro de tal forma que não o percebo como compositor de meu discurso e revelador da relação estabelecida entre produto e produtor, que emerge da relação mãe-filha. Justamente o que Valéria relata que a mãe não gosta nela - o fato de ficar sentada, ao invés de ajudar nas tarefas domésticas, ou fingir que está dormindo - é o que a mãe concebe como característica típica da adolescência, e que a torna, nas suas palavras, "a fase mais difícil".

E a concordância entre o que penso que o outro não gosta em mim e o que o outro diz não gostar, a respeito daquele certo grupo, demonstra como vou me constituindo enquanto sujeito e me reconhecendo no mundo a partir do encontro com o outro. Assim sendo, percebe-se que a imagem de si de Valéria, nesse contexto, é constituída a partir da fala de um outro, de sua mãe, que por sua vez ecoa muitas outras vozes sociais.

A voz de um outro que é muito presente nas falas das jovens é a voz onisciente da mídia. Essa voz é a voz que tece o desejo de ser atriz, por exemplo, e que está presente na construção dos projetos de vir a ser das jovens pesquisadas.

"Entrevistadora: O que tu queres ser quando crescer?

Fabiana: Atriz.

Entrevistadora: Atriz? E o que tu acha que tem que fazer para chegar a ser uma atriz?

Fabiana: Estudar, fazer curso”.

"Poliana: Eu acho que eu posso ser uma bailarina profissional ou uma artista da TV.

Entrevistadora: E tu tens vontade de ser uma bailarina ou uma artista?

Poliana: Aham”.

O desejo dessas jovens de tornarem-se atrizes, modelos, dançarinas, é mediado por valores e significados que são continuamente compartilhados em nossa sociedade pelos meios de comunicação de massa. Esses meios, entre os quais destacam-se a televisão e as telenovelas, disseminam a idéia e desejo de tornar-se parte dele para todos de forma igual, mesmo que as possibilidades e condições para todos não sejam iguais. Vendem a ilusão de uma vida intensa e isenta de preocupações mundanas, como a própria sobrevivência, ilusão que é consumida em doses diárias ao simples apertar de um botão.

Nesse contexto, é difícil falar de juventude sem considerar as contradições produzidas pela competição do grande mercado dos sentidos, como bem define Fischer ${ }^{18}$ em seu artigo sobre juventude e mídia. Comércio sutil, e ao mesmo tempo ávido, que possibilita a 
existência de uma íntima relação, interdependente e inter-relacionada, entre as vidas vividas e as vidas narradas por estes meios. Na trama dos discursos, transações mil são efetuadas, nas quais sentidos, valores, idéias, corpos, sensibilidades e modos de vida tornam-se produtos e são rapidamente consumidos pelos jovens.

Na sociedade do espetáculo e especulação televisivos, todo um imaginário vai sendo tecido coletivamente acerca do que pode e o que deve fazer o jovem brasileiro. Vozes silenciosas e imperativas que passam a compor e a se repetir nos discursos das jovens sobre elas mesmas, mas que desvelam tensões e contradições cotidianamente vividas pela grande maioria que possui condições de vida inversas àquelas dramatizadas.

Jovens meninas: histórias e percursos num bairro popular de Florianópolis

Devido à condição econômica e cultural de suas famílias e do contexto em que vivem, é possível dizer que as jovens entrevistadas constituem-se de maneira diferente de outros jovens, caracterizando e produzindo uma certa juventude. E dessa forma, as jovens significam sua realidade de acordo com o modo de vida, suas contradições e tensões, e o momento em que estão inseridas. ${ }^{7}$

Diversidades firmadas pelas diferentes formas de se colocar e se produzir enquanto sujeito social no percurso da juventude, bem como nos diferentes territórios simbólicos urbanos em que vivem. O bairro popular de Florianópolis onde esta pesquisa foi realizada possui conformações próprias. Com uma população de aproximadamente 5.000 habitantes, segundo censo do IBGE -2000, o bairro ocupa extensas áreas às margens de uma rodovia estadual e é formado por casas de baixo e médio padrão, conjuntos habitacionais construídos pelo governo e destinados à população de baixa renda, sedes administrativas de empresas, centros de entretenimento e um shopping.
Criados para suprir o problema de déficit habitacional dos centros urbanos, os conjuntos de moradias populares, nos quais residem as jovens entrevistadas desta pesquisa, geralmente casas de duas águas ou blocos de apartamentos, são destinados às famílias unicelulares da população de baixa renda dos municípios. As casas tão próximas umas das outras favorecem uma outra rede de relações familiares, comunitárias, com a cidade e seus serviços - na qual a vida comunitária se caracteriza pela vida sendo compartilhada intensamente com os vizinhos.

Como coloca Bourdieu" ${ }^{19}$, "Para compreender o que se passa em lugares que, como os 'conjuntos habitacionais' ou os 'grandes conjuntos', e também numerosos estabelecimentos escolares, aproximam pessoas que tudo separa, obrigando-as a coabitarem, seja na ignorância ou na incompreensão mútua, seja no conflito, latente ou declarado, com todos os sofrimentos que disso resultem, não basta dar razão de cada um dos pontos de vista tomados separadamente".

Nesses conjuntos habitacionais configuram-se territórios onde conflitos específicos são vivenciados, já que se precisa aprender a viver com os olhares, vozes, enfim, presenças, que entram na sua residência e na sua intimidade. Se a proposta inicial deste tipo de projeto era ter construções integradas ao espaço urbano com amplos espaços internos, sem circulação de automóveis, para aumentar o "espírito" de coletividade baseado na intensa convivência entre as pessoas ${ }^{20}$, o que se produziu foram moradias padronizadas, edificadas em regiões de alta criminalidade que, muitas vezes, aumentam a segregação de quem ali reside.

As casas repetidas, com as poucas marcas pessoais de seus moradores, possibilitam a construção de um olhar homogeneizante a quem por ali passa e mistura, mistura quem ali mora. O que aparenta uma estrutura só, o conjunto habitacional, na realidade representa 0 
lar, o afeto, os conflitos, as amizades, de inúmeras vidas, singulares e únicas.

A cidade também é discurso. A cidade por si constitui enunciados e enunciações, assim como bem coloca Bakhtin ${ }^{15}$ : constitui fatos sociais, concretos e contextualizados, que são produções ideológicas. Neste sentido, ao pensarmos nos espaços urbanos, consideramos que a distribuição de riquezas está relacionada com a distribuição das pessoas e os territórios.

Os espaços e a circulação de pessoas nos mesmos não ocorrem ao acaso, mas segue a uma dada ordem social, uma dada lógica capitalista. E estes espaços discursam a respeito das diferenças sociais vivenciadas por famílias como as das jovens entrevistadas, que vem à Florianópolis em busca de melhor qualidade de vida e de emprego. Esse fato acaba por promover grandes rupturas e muitos problemas, pois existe um certo conflito entre as famílias que são do bairro e as famílias que chegam, não se sabe de onde, com práticas sociais e costumes diversos.

A criminalidade faz parte da vida dessas jovens e do seu imaginário. Nada foi falado acerca disso nas entrevistas, mas o professor que ministrou a oficina de teatro relata que nos primeiros encontros com as jovens, elas falavam muito sobre morte e a respeito dos acontecimentos fatídicos do bairro. Relata que isso lhe causou um certo estranhamento; do ponto de vista delas, no entanto, esses fatos são cotidianos e comuns.

Pode-se dizer, então, que os espaços urbanos, sejam os forçosamente coletivos ou não, participam como discursos (ex)implícitos e vozes imperiosas na constituição dessas jovens meninas enquanto sujeitos inseridos em um determinado contexto sócio-econômico e cultural.

No sentido destas reflexões, não por acaso observa-se que o espaço da rua, da Associação de Moradores e da escola aparecem tão significativamente em nos discursos das jovens entrevistadas. São espaços extensão de suas casas. Ao se perguntar quais as características de um adolescente ou jovem para elas e o que elas faziam enquanto tal, Fabiana responde: "Participam do projeto", referindo-se às oficinas e cursos disponíveis na Associação de Moradores. Mônica, por sua vez, diz que "Jogam futebol, participam da Associação de Moradores e vão para a escola".

Interessante notar nestas falas como estes espaços fora de casa, principalmente a Associação de Moradores, são importantes na definição do que elas fazem enquanto jovens que são. Ser jovem é, então, participar e estar nestes locais. Certamente, nossas ações cotidianas e nossos lugares sociais constituem aquilo que somos, sendo estas ações realizadas em determinados contextos que as implicam.

Segundo Bakhtin"1, "os índices do tempo transparecem no espaço e o espaço reveste-se de sentido e é medido com o tempo". Entende-se com Bakhtin que as categorias espaços temporais são, também, centros organizadores dos principais acontecimentos temáticos de um enunciado. Os assuntos e os acontecimentos que permeiam a cena juvenil destas meninas são suscitados por meio de suas vivências em um tempo e espaço singulares, nas quais experienciam relações com outros jovens.

Espaços-tempos, com suas histórias e nossas histórias neles e por eles. Espaços-memórias onde gravamos em nós, nossos corpos e no que somos, as histórias neles vividas. Portanto, estes determinados lugares enunciados nos discursos destas jovens evidenciam também certas funções que lhes são atribuídas enquanto jovens sujeitos e também revelam um certo espaço-tempo, um certo contexto do acontecer.

\section{CONSIDERAÇÕES FINAIS}

No bairro popular de Florianópolis onde a pesquisa foi realizada, juventudes vão se fa- 
zendo nas fronteiras dos espaços públicos - ruas, associação, escola - e dos espaços privados, domésticos. Estes territórios tornam-se significativos na constituição dessas jovens como sujeitos, na elaboração singular produzida acerca de si mesmas, mas também as implica nos processos coletivos da localidade em que vivem.

Se estas jovens constituem-se continuamente a partir dos contextos sociais em que estão inseridas, nos quais o bairro popular e seus conjuntos habitacionais expressam as diferenças sociais da/na cidade e também as diferenças de juventudes; observou-se que as vozes e os discursos não respeitam limites geográficos, tampouco os sentidos que estes mesmos discursos fazem ecoar no urbano. Nas vozes das jovens entrevistadas, outras vozes se faziam ouvir.

\section{REFERÊNCIAS}

1. Abramo HW. Cenas juvenis, punks, darks no espetáculo urbano. São Paulo: Scritta; 1994.

2. Abramo HW, Freitas MV, Sposito MP (orgs.). Juventude em debate. São Paulo: Cortez; 2000.

3. Abramovay M, Waisselfisz JJ, Andrade CC, Rua M Gangues, galeras, chegados e rappers: juventude, violência e cidadania nas cidades da periferia de Brasília. Rio de Janeiro: UNESCO, Instituto Ayrton Senna, Setur e Gramond; 1999.

4. Castro MG, Abramovay M, Rua MG, Andrade E. Cultivando vida, desarmando violências: experiências em educação, cultura, lazer, esporte e cidadania com jovens em situações de pobreza. Brasília: UNESCO, Brasil Telecom, Fundação Kellog, Banco Interamericano de Desenvolvimento; 2001.

5. Mynaio MCS, Assis SG, Souza ER. Fala galera: juventude, violência e cidadania
O conhecimento construído até então acerca da temática juventude e o conseqüente imaginário coletivo criado; os discursos das famílias, amigos e mídia e o espaço em que vivem - considerando a cidade também como uma voz social entre tantas outras - são mediadores das imagens que as jovens constroem de si. Desse modo, essa pesquisa permite compreender a trama intrincada das relações e vozes sociais que participam no processo de constituição da imagem de si das jovens investigadas, o modo como se apropriam das falas de muitos outros e as objetivam em seus discursos e fazeres, sendo essas vozes constitutivas desses sujeitos no encontro (in)tenso com esses outros (re)(des)conhecidos.

na cidade do Rio de Janeiro. Brasília: UNESCO, Instituto Ayrton Senna, Fundação Ford, Fundação Osvaldo Cruz e Garamond; 1999.

6. Coimbra CC, Bocco F, Nascimento ML. Subvertendo o conceito de adolescência. Arquivos brasileiros de psicologia. 2005; 57(1): 2-11.

7. Dayrell J. O jovem como sujeito social. In: Revista Brasileira de Educação; 2003, 24: 40-52.

8. Abramo HW. Condição juvenil no Brasil contemporâneo. In: Abramo HW, Branco PPM (orgs). Retratos da juventude brasileira: análises de uma pesquisa nacional. São Paulo: Editora Fundação Perseu Abramo; 2005; p.37-72.

9. Borges CAM. Rede e inclusão social. In: $2^{\circ}$ congresso brasileiro de extensão universitária; 2004 Set 12 -15; Belo Horizonte/MG. Anais do $2^{\circ}$ congresso brasileiro de extensão universitária; 2004 Set 12 -15; Belo Horizonte/MG.

10. Azeredo B. Estratégia social em favelas e periferias urbanas. In: XV fórum nacional - o novo governo, novas 
prioridades e crescimento sustentado, 2003 Maio; Rio de Janeiro. Anais do XV fórum nacional - o novo governo, novas prioridades e crescimento sustentado; 2003 Maio; Rio de janeiro, p.1-24.

11. Castells M. A era da informação: economia, sociedade e cultura. Vol. II: o poder da identidade. São Paulo: paz e terra; 1999.

12. Coimbra C. Operação Rio: o mito das classes perigosas, um estudo sobre a violência urbana, a mídia impressa e os discursos de segurança pública. Niterói: intertexto/oficina do autor; 2001.

13. Ministério da Saúde. Marco Legal: saúde, um direito de adolescentes. Brasília: Ministério da Saúde, 2005.

14. Triviños ANS. Introdução à pesquisa em ciências sociais: a pesquisa qualitativa em educação. São Paulo: Atlas; 1987.
15. Bakhtin M. Marxismo e filosofia da linguagem. São Paulo: Hucitec; 1990.

16. Vigotski LS. Obras escogidas III: problemas del desarrollo de la psique. Madrid: visor distribuciones; 2000.

17. Traverso-yépez M. Os discursos e a dimensão simbólica: uma forma de abordagem à psicologia social. Estudos de psicologia; 1999, 4(1): 39-59.

18. Fischer RMB. Mídia e juventude: experiências do público e do privado na cultura. Cad. Cedes, Campinas; 2005; 25 (65): 43-58.

19. Bourdieu P. (org.). A miséria do mundo. 5. Ed. Petrópolis: vozes; 2003.

20. Carvalho LA, Lobo E, Stanley M. Questão Habitacional e Movimento Operário. Rio de Janeiro: UFRJ; 1989.

21. Bakhtin M. Questões de literatura e de estética: a teoria do romance. São Paulo: Hucitec e fundação para o desenvolvimento da UNESP; 1988.

Recebido em: 25 de novembro de 2008. Modificado em: 30 de março de 2009. Aceito em: 20 de agosto de 2009. 